\title{
Physical and economical aspects of Pu multiple recycling on the basis of REMIX reprocessing technology in thermal reactors
}

\author{
Pavel S. Teplov ${ }^{*}$, Pavel N. Alekseev, Evgeniy A. Bobrov, and Alexander V. Chibinyaev \\ NRC "Kurchatov Institute", Moscow, Russia
}

Received: 30 September 2015 / Received in final form: 30 March 2016 / Accepted: 20 September 2016

\begin{abstract}
The basic strategy of Russian nuclear energy is propagation of a closed fuel cycle on the basis of fast breeder and thermal reactors, as well as the solution of the spent nuclear fuel accumulation and resource problems. The three variants of multiple $\mathrm{Pu}$ and $\mathrm{U}$ recycling in Russian pressurized water reactor concept reactors on the basis of REgenerated MIXture of U, Pu oxides (REMIX) reprocessing technology are considered in this work. The REMIX fuel is fabricated from an unseparated mixture of uranium and plutonium obtained during spent fuel reprocessing with further makeup by enriched natural $\mathrm{U}$ or reactor grade $\mathrm{Pu}$. This makes it possible to recycle several times the total amount of $\mathrm{Pu}$ obtained from the spent fuel. The main difference in $\mathrm{Pu}$ recycling is the concept of $100 \%$ or partial fuel loading of the core. The third variant is heterogeneous composition of enriched uranium and uranium-plutonium mixed oxide fuel pins in one fuel assembly. It should be noted that all fuel assemblies with $\mathrm{Pu}$ require the involvement of expensive technologies during manufacturing. These three variants of the full core loadings can be balanced on zero $\mathrm{Pu}$ accumulation in the cycle. The various physical and economical aspects of $\mathrm{Pu}$ and $\mathrm{U}$ multiple recycling in selected variants are observed in the given work.
\end{abstract}

\section{Introduction}

The basic strategy of Russian nuclear energy is propagation of a closed fuel cycle on the basis of fast breeder and thermal reactors. The strategy can help to solve such systematic problems as the huge quantity of accumulated spent nuclear fuel (SNF) in the storages and the limited inventory of cheap natural uranium for fuel production, and to increase the economic attractiveness of the nuclear industry. There is a program based on the development of fast nuclear reactors in Russia, but this technology is not ready for global implementation. The main element of the nuclear power fleet in Russia today is Russian pressurized water reactor concept (VVER) reactors. The first stage for a closed fuel cycle can be done with applying thermal reactors. It will help to decrease the amount of SNF in storage, reduce natural uranium consumption and develop modern reprocessing technologies.

The most thoroughly elaborated technology for regenerated material implementation in thermal reactors is uranium-plutonium mixed oxide (MOX) fuel technology, the variant of plutonium mixing with depleted

\footnotetext{
* e-mail: pollteploff@dhtp.kiae.ru
}

uranium. The main problem of MOX fuel usage is the degradation of the $\mathrm{Pu}$ isotopic composition. Currently, once through cycling of $\mathrm{Pu}$ is carried out in pressurized water reactors (PWRs) in a MOX assembly partially loaded core.

The regenerated uranium received in the reprocessing process is stored or partly used. In Russia, the uranium separated from VVER-440 spent fuel is mixed with the uranium extracted from the BN-600 spent fuel and then used for fabricating RBMK fuel composition. It is important to note that the storage of regenerated $\mathrm{Pu}$ is very expensive.

In the papers [1-3], it has been proposed to use the fuel made from an unseparated mixture of the uranium and plutonium isotopes mixed with the enriched natural uranium in thermal reactors. Such fuel was called the REMIX-fuel (REgenerated MIXture of $\mathrm{U}, \mathrm{Pu}$ oxides). The main achievements of the REMIX technology are simplified reprocessing process, natural uranium savings, multiple recycling and the possibility of full core loading. In the papers [4,5], there have been proposed, some new variants of the REMIX-fuel based on different feeding and fissile materials like ${ }^{232} \mathrm{Th},{ }^{238} \mathrm{U},{ }^{233} \mathrm{U}$ and ${ }^{239} \mathrm{Pu}$. It has been shown that in the presence of constant feeding the fuel isotopic composition goes to an equilibrium state for all variants. 


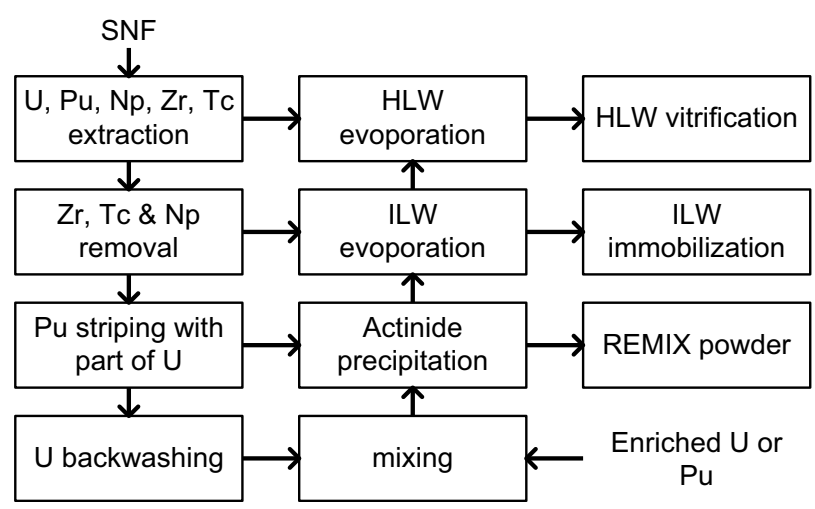

Fig. 1. The flowchart for fabrication of REMIX fuel.

Different $\mathrm{Pu}$ multirecycling strategies were observed during the last few years [6,7] across the world. The main difference of the above reports from the concepts presented in this paper is $\mathrm{Pu}$ content in the core and the reprocessing technology.

This paper shows the three different variants of $\mathrm{Pu}$ multiple recycling in VVER type reactors. The first two variants differ with feeding fissile material. The first is the standard REMIX fuel [1-3] approach and the second is close to MOX fuel where regenerated uranium is used instead of depleted uranium and the feeding fissile material is reactor grade plutonium. This makes it possible to recycle several times the total amount of $\mathrm{Pu}$ obtained from the spent fuel. The main difference in $\mathrm{Pu}$ recycling is the concept of $100 \%$ or partial fuel assemblies (FAs) loading of the core. The third variant is a heterogeneous composition of enriched uranium and MOX fuel pins in the FA. These three variants of the full core loadings are balanced on zero $\mathrm{Pu}$ accumulation in the fuel cycle. All the $\mathrm{Pu}$ from the spent fuel of the core loading is used to produce new fuel for the next loading. This approach makes it possible to compare physical and economic aspects of the three variants of $\mathrm{Pu}$ multiple recycling in the VVER core.

The neutron-physics calculations were performed by the Consul code package [8]. All calculations were performed for the standard VVER-1000 FA [9] configuration. The duration of the fuel campaign is 4 years $(4 \times 300$ EFPD (effective full-power days)) with an average burnup of $49.3 \mathrm{MW}$ day $/ \mathrm{kg}_{\mathrm{HM}}$.

\section{Concepts of $\mathrm{Pu}$ multiple recycling}

The concept of REMIX fuel application for VVER type reactors was developed in Russia. REMIX fuel is fabricated from an unseparated mixture of uranium and plutonium obtained during the SNF reprocessing process with the further addition of fissile material fraction to maintain the fissile property of the recycled fuel. The main reprocessing process is shown in Figure 1 [1].

During the reprocessing process, minor actinides (MA) and fission products are removed for further disposal. The unseparated mixture of uranium and plutonium can be obtained as a regular solid solution of $\mathrm{PuO}_{2}$ in $\mathrm{UO}_{2}$ by precipitation or by direct thermal or thermochemical

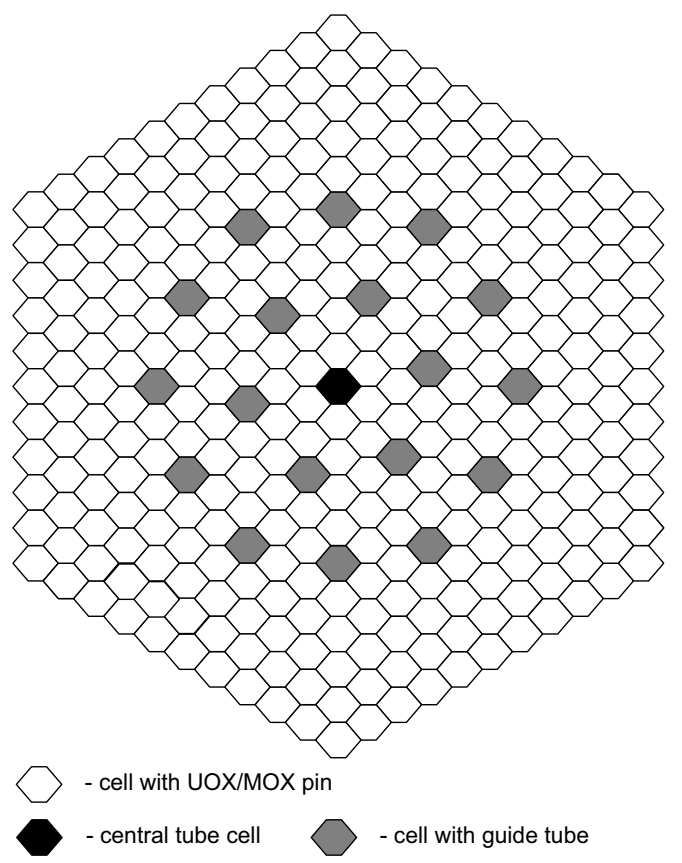

Fig. 2. The standard VVER-1000 FA configuration for REMIX, REMIX(MOX) variants.

denitration of the evaporated joint $\mathrm{U}$ and $\mathrm{Pu}$ backwash. This technology process is going to be performed at the experimental-demonstration center (EDC) being under construction now in Zheleznogorsk. The powder preparation at the reprocessing facility can improve the quality of fuel composition and decrease the cost of FA fabricating.

The first variant observed in this paper is based on enriched uranium addition to the recycled mixture of $U$ and $\mathrm{Pu}$. Basically, the enrichment of feeding $\mathrm{U}$ is supposed to be less than $20 \%$ of ${ }^{235} \mathrm{U}$, but it will be impossible to achieve $100 \%$ usage of spent fuel for the next loading in that case. The first selected variant presumes enrichment of feeding $\mathrm{U}$ in the range of $50-55 \%$ of ${ }^{235} \mathrm{U}$ to achieve the parameters given in the task. That is the standard REMIX fuel concept. The resulting mixture consists of $3.8 \%$ of ${ }^{235} \mathrm{U}$ and $1.2 \%$ of $\mathrm{Pu}$. The $\mathrm{Pu}$ and ${ }^{235} \mathrm{U}$ content grow with recycling number. This variant assumes $100 \%$ loading of the core with REMIX FAs.

The second variant is based on $\mathrm{Pu}$ addition to the mixture. The necessary amount of $\mathrm{Pu}$ is received from the pre-recycled FA with standard uranium oxide (UOX) fuel. It is possible to achieve $100 \%$ usage of spent fuel in this case. The second variant needs additional reprocessing of UOX fuel with full separation of the plutonium fraction. The main difference from the standard MOX fuel is the presence of regenerated $U$ instead of depleted $U$. The resulting mixture consists of $0.8 \%$ of ${ }^{235} \mathrm{U}$ and $9 \%$ of $\mathrm{Pu}$. The investigation of FA depletion was done under the assumption that MOX FA is surrounded with UOX FAs to take into account spectral effects.

The standard construction of the VVER-1000 FA with 312 fuel pins (Fig. 2) was chosen for the investigation of burnup properties of new fuel compositions for the first and second variants. No burnable absorbers or $\mathrm{Pu}$ content profiling were taken into account. 


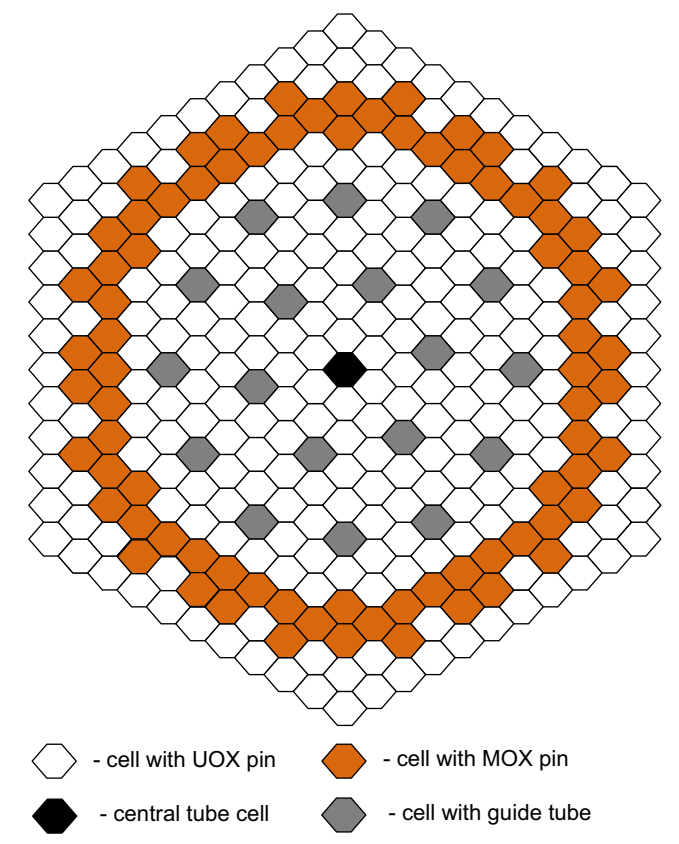

Fig. 3. The REMIX (het) FA configuration for heterogeneous fuel pin positioning.

The third variant is based on the facts that during reprocessing the full FA is cut and melted down and that REMIX technology allows the obtaining of a mixture with any $\mathrm{Pu}$ content (Fig. 1). The main idea was to separate UOX and MOX fuel pins in the REMIX FA to achieve better fission properties for ${ }^{235} \mathrm{U}$. The variant of heterogeneous fuel pin positioning for the VVER FA is presented in Figure 3. This concept is close to the CORAIL FA design for $\mathrm{Pu}$ multirecycling in PWR [6,7]. The main difference is the MOX fuel pin amount in FA and regenerated $U$ presence in fuel composition which helps to reduce the $\mathrm{Pu}$ content in MOX fuel pins.

The presented FA consists of 78-90 MOX fuel pins (25\%) with $0.8 \%$ of ${ }^{235} \mathrm{U}$ and $4.5 \% \mathrm{Pu}$ and $234-222 \mathrm{UOX}$ fuel pins with $4.6 \%$ of ${ }^{235} \mathrm{U}$. The Pu content in the MOX fuel pin, the total number and the positioning of these pins in the FA were chosen to meet the following tasks:

- the average burn-up of MOX and UOX fuel pins are equal;

- the peaking factor does not exceed 1.2 (assembly calculation).

The total amount of $\mathrm{Pu}$ and MOX pins will increase with recycling number. The investigation doesn't assume the usage of regenerated uranium for UOX pin manufacturing, and they have standard design.

\section{The physical aspects of $\mathrm{Pu}$ multiple recycling}

As abovementioned, the main principle of physical and economical comparison for selected variants of $\mathrm{Pu}$ multiple recycling is zero $\mathrm{Pu}$ accumulation in the fuel cycle. All the $\mathrm{Pu}$ from the spent fuel of the core loading is used to produce new fuel for the next loading so it is possible to speak about fuel balance in the nuclear system. The main conditions for

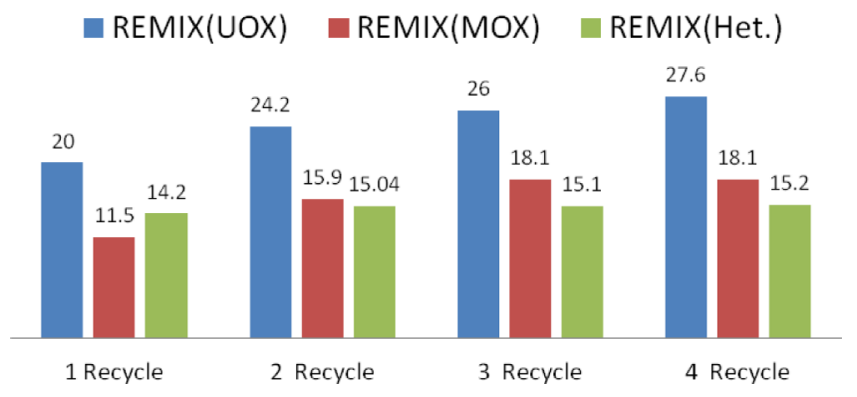

Fig. 4. The natural uranium consumption reduction, $\%$.

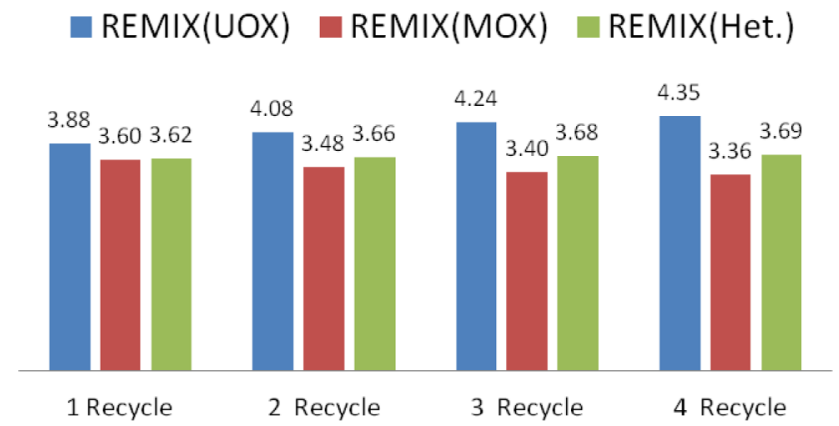

Fig. 5. Integral ${ }^{235} \mathrm{U}$ content for the core fuel loading, $\%$.

the fuel loading burnup calculations are equal. The duration of the fuel campaign is 4 years $(4 \times 300 \mathrm{EFPD})$ with the average burnup $49.3 \mathrm{MW}$ day $/ \mathrm{kg}_{\mathrm{HM}}$. Four recycles were observed to receive a close to equilibrium balance of isotopes. 5 years cooling time was chosen for SNF before reprocessing. The same results for UOX FA can be achieved with $4.1 \%$ enrichment of $\mathrm{U}$ in the fuel.

The main characteristic for the fuel balance comparison is the natural uranium consumption. All variants require additional resources of enriched U. Figure 4 shows the natural uranium consumption reduction for selected variants. The economy coefficient for MOX FA can be calculated with the following equation:

$$
\text { Economy }=\frac{\mathrm{FA}_{\max }}{\mathrm{FA}_{\mathrm{UOX}+\mathrm{MOX}}}=\frac{1}{1+\frac{\text { additional Pu for MOX }}{\text { Pu content in UOX SNF }}} \cdot(1)
$$

It can be noted that the standard REMIX approach gives the best result in uranium consumption reduction, because of the multiple usage of all amounts of the regenerated uranium in the fuel matrix and the concentration of ${ }^{235} \mathrm{U}$ is increasing with the recycling number (Fig. 5). The performance of REMIX(MOX) and REMIX(het.) variants can be improved by regenerated uranium usage in UOX fuel. The preliminary calculations shows that the REMIX(het.) variant of $\mathrm{Pu}$ multirecycling gives comparable performance to the REMIX(UOX) variant in the case of natural uranium consumption reduction.

Figure 5 shows the integral parameter of ${ }^{235} \mathrm{U}$ content in the fuel loading.

It is difficult to compare all variants in the case of ${ }^{235} \mathrm{U}$ content because standard REMIX(UOX) fuel contains regenerated uranium fraction. 


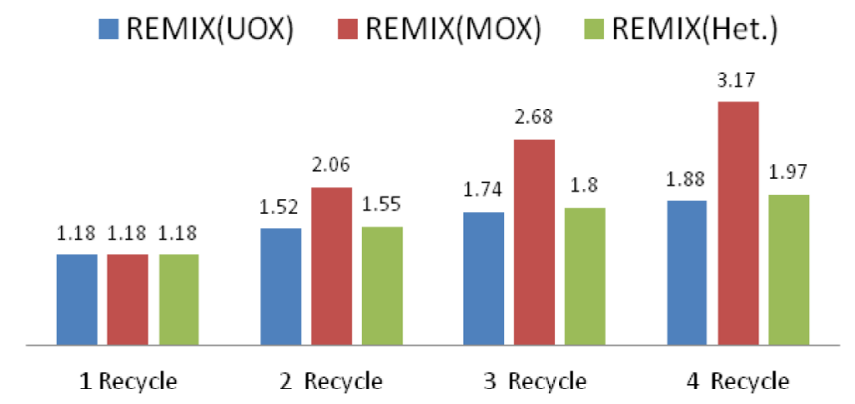

Fig. 6. Integral plutonium content for the core fuel loading, $\%$.

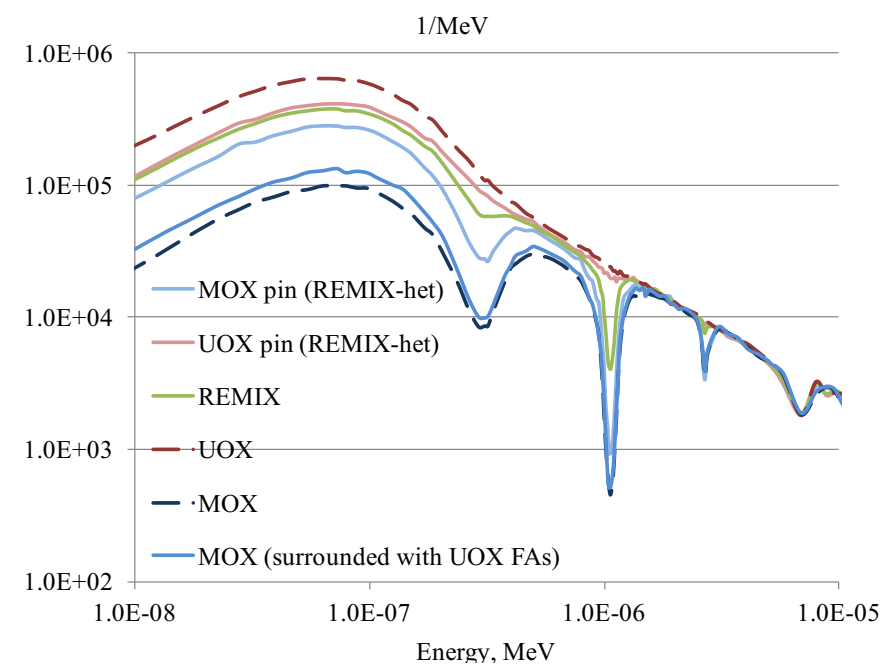

Fig. 7. Spectrum effects for different fuel compositions.

Figure 6 shows the integral parameter of $\mathrm{Pu}$ content in the fuel loading. Starting with the first recycle, where this parameter is equal for all variants, $\mathrm{Pu}$ content changes with the recycle number due to the different breeding ratio for the chosen systems. The integral Pu content for REMIX (MOX) variant can be calculated with the following equation:

$$
\text { integral Pu content }=\text { Economy } \times \mathrm{Pu} \text { content in FA. }
$$

The rapid increase of $\mathrm{Pu}$ content in the system for REMIX(MOX) variant can be explained by the degradation of isotopic composition and hard spectrum conditions. The average $\mathrm{Pu}$ content in MOX FA changes from 9.5 to $16.5 \%$. The $\mathrm{Pu}$ content in the peripheral row of fuel pins should be two times lower than in the central part of FA. High integral plutonium content relates to high MA content.

$\mathrm{Pu}$ content in the MOX fuel pin for the heterogeneous FA grows from $4.5 \%$ to $5.4 \%$ by the 4 th recycle.

Figure 7 shows the differences in spectra which are important for burn-up properties of chosen fuel compositions.

All spectral lines are located between MOX and UOX variants. The MOX spectrum has a lower amount of thermal neutrons due to the presence of absorbing peaks at $\mathrm{Pu}$ isotopes close to the thermalization region. The
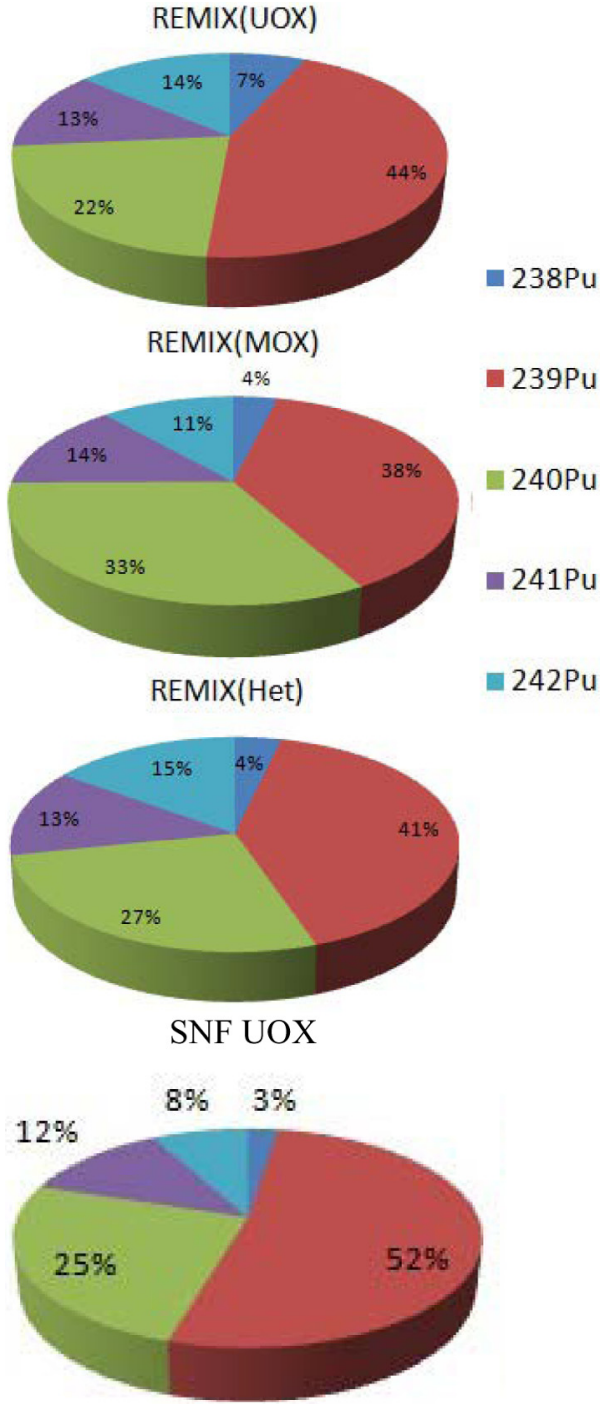

Fig. 8. The close to the equilibrium $\mathrm{Pu}$ isotopes configuration for fresh fuel compositions in comparison with plutonium in SNF from UOX fuel, \%.

influence of surrounded FAs with UOX fuel on the spectrum of the MOX FA is not very high. The main effect can be observed in peaking factors for peripheral rows of MOX pins so $\mathrm{Pu}$ content profiling should be applied to FA. The spectrum of fresh REMIX fuel (green line) is similar to burned UOX fuel because of the small $\mathrm{Pu}$ content. The great influence in a thermal spectrum can be observed for MOX fuel pins in a heterogeneous configuration of FA. Therefore, a small amount of $\mathrm{Pu}$ is needed to achieve the same fissile properties.

The comparison of $\mathrm{Pu}$ isotopic composition in fresh fuel for the 4 th recycle with plutonium in SNF from UOX fuel is presented in Figure 8.

A significant degradation of $\mathrm{Pu}$ isotopic composition can be noticed for REMIX(MOX) variant.

The multirecycling of regenerated uranium in the fuel matrix is a complex problem. For REMIX(UOX) fuel, the limitation of natural uranium consumption reduction is associated with ${ }^{236} \mathrm{U}$ concentration growth. In addition, it 


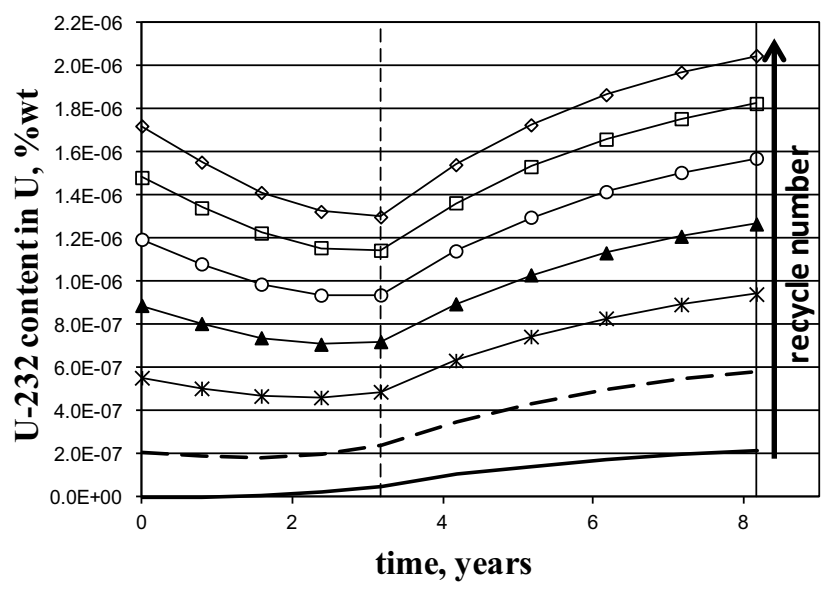

Fig. 9. The ${ }^{232} \mathrm{U}$ content in REMIX(UOX) fuel.

Table 1. Radiation and thermal exposure comparison for fresh fuel in FA.

\begin{tabular}{llllclll}
\hline Variant & $\begin{array}{l}\text { REMIX } \\
\text { (UOX) }\end{array}$ & \multicolumn{2}{l}{$\begin{array}{l}\text { REMIX } \\
\text { (MOX) }\end{array}$} & \multicolumn{2}{l}{$\begin{array}{l}\text { REMIX } \\
\text { (het) }\end{array}$} \\
\hline Recycling number & 1 & 4 & 1 & 4 & 1 & 4 \\
Radiation exposure & 1.0 & 3.2 & 5.7 & 13.4 & 1.0 & 2.6 \\
Thermal exposure & 1.0 & 4.0 & 5.3 & 14.4 & 1.0 & 3.1 \\
\hline
\end{tabular}

is important to mention ${ }^{232} \mathrm{U}$ concentration growth (Fig. 9), which is important for radiation safety. ${ }^{232} \mathrm{U}$ and ${ }^{238} \mathrm{Pu}$ make the basic contribution in the radiation (adsorbed) dose.

The actual limit for ${ }^{232} \mathrm{U}$ concentration will be achieved on the second recycling stage. The same problem can be observed with uranium recycling in the case of reenrichment in UOX fuel.

Table 1 shows the integral for FA comparison of radiation and thermal exposure with REMIX fuel in relative units.

The results show that the main difficulties with fresh FA treatment will be observed for the REMIX(MOX) variant due to the high concentration of $\mathrm{Pu}$ in the fuel matrix. The first recycle results for standard REMIX (UOX) and REMIX(het) are close, but the situation changes with recycling number. REMIX(het) variants have smaller integral for FA concentration of ${ }^{232} \mathrm{U}$ and ${ }^{238} \mathrm{Pu}$ isotopes which are responsible for high values of radiation and thermal exposure.

\section{The economical aspects of Pu multiple recycling}

From the economical point of view, it is important to compare results with the standard opened fuel cycle for UOX fuel. The costs for different stages of fuel cycle are taken from different sources [10-12] with expert evaluation. Table 2 shows the basic UOX FA cost calculation. The additional calculation parameters were chosen: $5 \%$ discount rate, $0.5 \%$ manufacturing losses.
Table 2. FA cost calculation parameters for UOX fuel.

\begin{tabular}{lll}
\hline & Value & Unit \\
\hline Fuel cycle costs & & \\
Natural uranium cost & 100 & $\$ / \mathrm{kg}_{\mathrm{U}}$ \\
Conversion cost & 10 & $\$ / \mathrm{kg}_{\mathrm{U}}$ \\
SWU cost & 110 & $\$ / \mathrm{SWU}$ \\
FA manufacturing cost & 330 & $\$ / \mathrm{kg}_{\mathrm{hm}}$ \\
Fuel properties & & \\
Enrichment & 4.1 & $\mathrm{wt} . \%$ \\
FA mass & 445.6 & $\mathrm{~kg}$ \\
Depleted U & 0.2 & $\mathrm{wt} . \%$ \\
Natural uranium consumption & 7.6 & $\mathrm{~kg} / \mathrm{kg}_{\mathrm{hm}}$ \\
SWU & 6.8 & $\mathrm{SWU} / \mathrm{kg}_{\mathrm{hm}}$ \\
Specific components & & \\
C(Unat) & 770.8 & $\$ / \mathrm{kg}_{\mathrm{hm}}$ \\
C(conv.) & 76.7 & $\$ / \mathrm{kg}_{\mathrm{hm}}$ \\
C(SWU) & 748.6 & $\$ / \mathrm{kg}_{\mathrm{hm}}$ \\
Specific FA cost & 2056.5 & $\$ / \mathrm{kg}_{\mathrm{hm}}$ \\
FA cost & 916414 & $\$ / \mathrm{ps}$ \\
\hline
\end{tabular}

Table 3. SNF backend costs calculation.

\begin{tabular}{lcl}
\hline & Value & Unit \\
\hline Transportation cost & 50 & $\$ / \mathrm{kg}_{\mathrm{hm}}$ \\
Storage cost & 5 & $\$ / \mathrm{kg}_{\mathrm{hm}}$ year \\
Final disposal cost & 500 & $\$ / \mathrm{kg}_{\mathrm{hm}}$ \\
SNF treatment cost & 750 & $\$ / \mathrm{kg}_{\mathrm{hm}}$ \\
\hline
\end{tabular}

The resulting price for FA is close to $\$ 0.9$ million. It is important to note the small cost of fuel manufacturing. The major expenses are associated with the natural uranium and enrichment costs.

The main problem of the opened fuel cycle is SNF treatment. The huge quantity of accumulated SNF is stored in the intermediate storage facilities. The backend SNF cost calculation is presented in Table 3. Intermediate SNF storage is not expensive. It is assumed 40 years storage before final disposal. No discount rate was taken into account, due to the high time intervals. High time intervals lead to great uncertainties and economical risks, and it is difficult to prove the possibility of long-term cash accumulating.

The integral cost of backend for SNF is 33\% from fresh FA cost. There is a significant uncertainty in backend cost calculation because of a lack of final disposal experience for SNF FAs in the world.

REMIX reprocessing technology leads to closed fuel cycle economics. The assumption of $\mathrm{Pu}$ "zero" cost was taken into account. Table 4 shows the main specific costs of manufacturing processes for REMIX FA fabrication taken in the investigation.

As can be noted, the specific cost for the standard REMIX fuel manufacturing process was taken lesser then for MOX fuel fabricating. This fact takes into consideration 
Table 4. Specific costs of manufacturing processes for REMIX FA fabrication.

\begin{tabular}{lcl}
\hline & Value & Unit \\
\hline Transportation cost & 50 & $\$ / \mathrm{kg}_{\mathrm{hm}}$ \\
Reprocessing cost & 700 & $\$ / \mathrm{kg}_{\mathrm{hm}}$ \\
UOX FA manuf. cost & 330 & $\$ / \mathrm{kghm}_{\mathrm{hm}}$ \\
REMIX(MOX) manuf. cost & 1500 & $\$ / \mathrm{kg}_{\mathrm{hm}}$ \\
REMIX(UOX) FA manuf. cost & 1000 & $\$ / \mathrm{kg}_{\mathrm{hm}}$ \\
REMIX(het) FA manuf. cost & 622.5 & $\$ / \mathrm{kg}_{\mathrm{hm}}$ \\
HLW treatment cost & 150 & $\$ / \mathrm{kg}_{\mathrm{hm}}$ \\
\hline
\end{tabular}

Table 5. The specific cost for the fabricating process of the core loading (1st recycle).

\begin{tabular}{lcrrr}
\hline & $\begin{array}{l}\text { REMIX } \\
\text { (UOX) }\end{array}$ & $\begin{array}{r}\text { REMIX } \\
\text { (MOX) }\end{array}$ & $\begin{array}{l}\text { REMIX } \\
\text { (het) }\end{array}$ & Unit \\
\hline Natural U savings & 20 & 11.5 & 14.2 & $\%$ \\
$\begin{array}{l}\text { Specific U cost for } \\
\text { the loading }\end{array}$ & 1374.7 & 1820.1 & 1478.3 & $\$ / \mathrm{kg}_{\mathrm{hm}}$ \\
$\begin{array}{l}\text { Specific cost for } \\
\text { the loading }\end{array}$ & 3334.4 & 2931.9 & 3051.2 & $\$ / \mathrm{kg}_{\mathrm{hm}}$ \\
$\begin{array}{l}\text { Difference with UOX } \\
\text { FA management }\end{array}$ & 1277.8 & 875.3 & 994.6 & $\$ / \mathrm{kg}_{\mathrm{hm}}$ \\
\hline
\end{tabular}

the simplification of the powder preparation process and the low plutonium content in the fuel matrix. The cost of REMIX(MOX) manufacturing is high due to the high plutonium concentration and can be higher with plutonium content rising. The REMIX(het) FA manufacturing cost was taken as the proportion of MOX and UOX fuel fabrication costs taking into account MOX pins number in the FA. The high-level waste (HLW) treatment cost was chosen as $1 / 5$ of the SNF treatment, but it is obvious that it will be greater for the REMIX(MOX) variant due to the higher content of MA. This assumption is based on the fact of the waste volume reduction. Modern reprocessing technologies can give even better results.

The resulting comparison of economic investigations presented in Tables 5 and 6. REMIX(UOX) and REMIX (het) variants suggest $100 \%$ loading of FA in the core. The REMIX(MOX) part in the core loading is equal to the savings of natural uranium value. The selected parameters of the study suggest the equal value of reprocessing SNF fuel for all variants. In the case of the REMIX(MOX) variant, MOX and UOX FAs should be reprocessed. The specific $U$ cost for the loading is the price of the enriched $\mathrm{UO}_{2}$ fraction taking into account uranium savings or UOX FAs fraction in the core in the case of the REMIX(MOX) variant. The necessary increase of uranium fuel pins enrichment due to the spectrum changes is taken into account for REMIX(MOX) and REMIX(het) variants. Difference with UOX FA management should be compared with SNF treatment cost which is equal to $750 \$ / \mathrm{kg}_{\mathrm{hm}}$.
Table 6. The comparison of specific cost for the loading (4th recycle).

\begin{tabular}{lrrrl}
\hline & $\begin{array}{l}\text { REMIX } \\
\text { (UOX) }\end{array}$ & $\begin{array}{r}\text { REMIX } \\
\text { (MOX) }\end{array}$ & $\begin{array}{l}\text { REMIX } \\
\text { (het) }\end{array}$ & Unit \\
\hline $\begin{array}{l}\text { Natural U savings } \\
\text { Specific U cost for }\end{array}$ & 124.6 & 18.1 & 15.2 & $\%$ \\
$\begin{array}{l}\text { the loading } \\
\begin{array}{l}\text { Specific cost for the } \\
\text { loading }\end{array}\end{array}$ & 1684.4 & 1475.1 & $\$ / \mathrm{kg}_{\mathrm{hm}}$ \\
$\begin{array}{l}\text { Difference with UOX } \\
\text { FA management }\end{array}$ & 1147.2 & 841.0 & 1027.3 & $\$ / \mathrm{kg}_{\mathrm{hm}}$ \\
\hline
\end{tabular}

The results shows that the REMIX(UOX) variant is the most expensive despite the greater uranium savings. The REMIX(MOX) variant shows the most positive result in comparison with the opened fuel cycle with direct disposal of SNF but the plutonium content in the core is increasing with recycling number growth. The heterogeneous FA configuration is more expensive than the REMIX(MOX) variant but gives the possibility of multiple $\mathrm{Pu}$ recycling comparable with standard REMIX(UOX) technology. The main disadvantage of the REMIX (het) variant is the need of the higher UOX fuel pins enrichment value. These results are very sensitive to the initial data, in particular as to FA manufacturing cost, but nevertheless, it is obvious that it is cheaper to use expensive fuel in the expensive FA. The integral cost for the closed fuel cycle decreases with the recycle number growth. If we take into account the usage of regenerated uranium for UOX fuel pin manufacturing the economic savings will increase for REMIX(MOX) and REMIX(het) variants.

The future growth of natural uranium cost can lead to better economics parameters in the closed fuel cycle. In addition, the SNF treatment requires the construction of long-term storages and final disposal facilities for the large amount of SNF which is very difficult to license. It is important to note that the fuel component is not determinant for the nuclear power plant (NPP) electricity cost and some external considerations about SNF treatment can be more significant.

\section{Conclusions}

The proposed above approach to the reprocessing technology has the potential to improve economic parameters by reducing the number of process steps during SNF reprocessing and fuel manufacturing (reducing the several stages of fuel powder and pellet fabrication as compared to MOX fuel fabrication). The new technology process can provide better quality for the mixed uranium-plutonium pellet fabrication. Low $\mathrm{Pu}$ content in the core has negligible influence on safety parameters of the NPP.

There are three options of REMIX FA fabrication proposed in the paper. All considered variants assume $\mathrm{Pu}$ multiple recycling. The $\mathrm{Pu}$ content and isotopic quality in the fuel matrix stabilized with growth of recycle number for 
most variants. The better results in natural uranium savings can be achieved for the standard REMIX(UOX) approach. The usage of regenerated materials in thermal power reactors gives not more than $30 \%$ saving of natural uranium consumption.

Estimation of technical and economic assessment presented in the paper has demonstrated that the use of REMIX technology in the closed fuel cycle is more expensive than the open fuel cycle with direct SNF disposal. The $\mathrm{Pu}$ positioning in the expensive MOX FA gives better results from an economic point of view but it is worse for multiple recycling. The main idea is to place expensive fuel in the expensive fuel pins or FAs so the integral FA cost for the loading will decrease.

It is important to note that the uranium multiple recycling in the REMIX fuel form or using the reenrichment process leads to the uranium isotope composition degradation. The ${ }^{236} \mathrm{U}$ and ${ }^{232} \mathrm{U}$ concentrations in the fuel are increasing and the regenerated uranium treatment becomes more complicated.

\section{Nomenclature}

$\begin{array}{ll}\text { EFPD } & \text { effective full-power days } \\ \text { FA } & \text { fuel assembly } \\ \text { HLW } & \text { high-level waste } \\ \text { MA } & \text { minor actinides } \\ \text { MOX } & \text { uranium-plutonium mixed oxide } \\ \text { NPP } & \text { nuclear power plant } \\ \text { PWR } & \text { pressurized water reactor } \\ \text { REMIX } & \text { REgenerated MIXture of U, Pu oxides } \\ \text { SNF } & \text { spent nuclear fuel } \\ \text { UOX } & \text { uranium oxide } \\ \text { VVER } & \text { Russian pressurized water reactor concept }\end{array}$

\section{References}

1. A.M. Pavlovichev, V.I. Pavlov, Y.M. Semchenkov, E.G. Kudryavtsev, Y.S. Fedorov, B.A. Bibichev, Neutron-physical characteristics of a VVÉR core with $100 \%$ load of reprocessed uranium and plutonium fuel, Atom. Energy 101, 863 (2006)
2. A.M. Pavlovichev, V.I. Pavlov, Y.M. Semchenkov, E.G. Kudryavtsev, Y.S. Fedorov, B.A. Bibichev, B.Y. Zil'berman, Neutron-physical characteristics of a WWER-1000 core with $100 \%$ fuel load consisting of a mixture of recovered uranium and plutonium and enriched uranium, Atom. Energy 104, $257(2008)$

3. Y.S. Fedorov, M.V. Baryshnikov, B.A. Bibichev, B.Y. Zilberman, O.V. Kryukov, A.V. Khaperskaya, Multiple recycle of REMIX fuel based on reprocessed uranium and plutonium mixture in thermal reactors, in Proceedings of Global 2013, Salt Lake City, Utah, September 29-October 3 (2013)

4. P.N. Alekseev, E.A. Bobrov, A.V. Chibinyaev, P.S. Teplov, A.A. Dudnikov, Variants of the perspective closed fuel cycle, based on Regenerated Mixture - Technology, combining use of thermal and fast reactors, Prog. Nucl. Energy 72, 126 (2014)

5. P.N. Alekseev, E.A. Bobrov, P.S. Teplov, A.V. Chibinyaev, Perspective variants of closed fuel cycle based on REMIX technology in two components system of nuclear power, Preprint NRC KI, IAE-6730/5, Moscow, 2012

6. J.P. Grouiller, J.Y. Doriath, A. Vasile, A. Zaetta, Different possible scenarios for plutonium recycling in PWRs, in Global 2001, Paris, France, INIS-FR-1314 (2001)

7. G. Youinou, A. Vasile, Plutonium multirecycling in standard PWRs loaded with evolutionary fuels, Nucl. Sci. Eng. 151, 25 (2005)

8. A.V. Chibinyaev, P.S. Teplov, CONSUL - code package for comprehensive LWR core calculations, in ICAPP 2007 Nice, France, May 13-18 (2007)

9. S.B. Vygovskyy, N.O. Ryabov, A.A. Semenov, E.V. Chernov, L.N. Bogachek, The physical and structural characteristics of nuclear power plants with VVER, in Textbook (MEPhI, Moscow, 2011)

10. D.E. Shropshire, K.A. Williams, J.D. Smith, B.W. Dixon, M. Dunzik-Gougar, R.D. Adams, D. Gombert, J.T. Carter, E. Schneider, D. Hebditch, Advanced fuel cycle cost basis (Idaho National Laboratory Report, INL/EXT-07-12107 Rev. 2, 2009)

11. OECD, The Economics of the Back End of the Nuclear Fuel Cycle (OECD, Nuclear Development, NEA No. 7061, 2013)

12. G. De Roo, J.E. Parsons, Economics of the Fuel Cycle (MIT Center for Energy and Environmental Policy Research, Viewgraph Presentation May 1, 2009)

Cite this article as: Pavel S. Teplov, Pavel N. Alekseev, Evgeniy A. Bobrov, Alexander V. Chibinyaev, Physical and economical aspects of $\mathrm{Pu}$ multiple recycling on the basis of REMIX reprocessing technology in thermal reactors, EPJ Nuclear Sci. Technol. 2, 41 $(2016)$ 